\title{
UM CARRO, QUEIMADO, NA BERMA DA ESTRADA: A EXPERIÊNCIA DE UM LABORATÓRIO DE ESCRITA PARA TEATRO*
}

\section{A CAR, BURNT-OUT, ON THE ROADSIDE: THE EXPERIMENT OF A THEATRE WRITING LABORATORY}

\author{
http://dx.doi.org/10.11606/issn.2175-3180.v12i23p166-184
}

Rui Pina Coelho ${ }^{\mathrm{I}}$

\section{RESUMO}

Este texto faz o balanço do Laboratório de Escrita para Teatro, promovido pelo Teatro Nacional D. Maria II (Lisboa), que coordenei de Setembro de 2015 a Setembro de 2019. Nesses quatro anos foram escritos vinte e três textos originais para teatro por vinte e três novos autores. $\mathrm{O}$ projecto surge integrado num programa mais lato de apoio a dramaturgias emergentes e ao incentivo à nova dramaturgia portuguesa, consistindo, neste caso, na aproximação de jovens autores dramáticos a processos de partilha, experimentação e colaboração que possam desafiar, influenciar e estimular a escrita original de um texto para teatro. Na primeira edição (2015/16) andámos em torno de "Um estado de excepção permanente", sob a égide de Terry Eagleton (2003) e da ideia de que a dramaturgia contemporânea não tem outra hipótese senão dar conta do estado de guerra - um estado de excepção permanente - entre os indivíduos e as instituições de poder. Na segunda edição (2016/17) fomos questionando "A política de tudo", num gesto de homenagem aos cem anos da Revolução de Outubro e de uma inquirição das contradições do século XX, inspirados pela lição de Alain Badiou (2005). Na terceira edição (2017/18) demorámo-nos $\mathrm{n}^{\prime}$ "O quotidiano do homem comum e outras coisas sem importância", conduzidos pela reflexão de Jean-Pierre Sarrazac em torno da poética da dramaturgia contemporânea e das suas "microepopeias dos anónimos". Na quarta edição (2018/19), quisemos "Interromper o real para a ele regressar", confiando nos possíveis gestos políticos que o teatro pode compreender.

\section{PALAVRAS-CHAVE}

Escrita para Teatro; Laboratório de Escrita; Dramaturgia Portuguesa; Crise do Drama

\section{ABSTRACT}

This article reflects about the Theatre Writing Laboratory, promoted by the National Theatre D. Maria II (Lisbon), which I coordinated from September 2015 to September 2019. In these four years, twenty-three new playwrights wrote twenty-three original plays. The project is part of a broader program to support emerging dramaturgies and to encourage the new Portuguese dramaturgy, consisting, in this case, in the approach of young dramatic authors to processes of sharing, experimentation and collaboration that can challenge, influence and stimulate the original writing of a text for theatre. In the first edition (2015/16) we walked around "A state of permanent exception", under the aegis of Terry Eagleton (2003) and the idea that contemporary dramaturgy has no choice but to account for the state of war - a state of permanent exception - between individuals and institutions of power. In the second edition (2016/17), we questioned "The politics of everything", in a gesture of homage to the hundred years of the October Revolution and an inquiry into the contradictions of the 20th century, inspired by the lesson of Alain Badiou (2005). In the third edition (2017/18) we lingered on "The daily life of the common man and other unimportant things", led by JeanPierre Sarrazac's reflection on the poetics of contemporary dramaturgy and his "microepopies of the anonymous". In the fourth edition (2018/19), we wanted to "Interrupt the real to return to it", trusting in the possible political gestures that the theatre can understand.

\section{KEYWORDS}

Writing for Theatre; Writing Laboratory; Portuguese Dramaturgy; Crisis of Drama

\footnotetext{
* Este texto é elaborado a partir dos quatro prefácios dos quatro livros que reúnem as peças escritas no âmbito do Laboratório de Escrita para Teatro, publicadas numa parceria entre o Teatro Nacional D. Maria II e a editora Bicho do Mato em 2016, 2017, 2018 e 2019.

I Universidade de Lisboa, Lisboa, Portugal.
} 
O preço da liberdade é a eterna vagabundagem.

Terry Eagleton (2003)

Deixemo-nos ser tentados pela amante do momento: a História.

Alain Badiou (2014)

A tragédia é, então, a consequência do impulso total do homem para se valorizar justamente.

Arthur Miller (1949)

Nothing is the way it stays.

Heiner Müller

\section{1.}

Um dos mais extraordinários equívocos sobre a dramaturgia portuguesa é que ela não existe. Que não temos a necessária "tête dramatique", como alegava Almeida Garrett, em 1822 (apud Rebello 2000, p. 13). Foi-se construindo uma narrativa de carapaça relativamente robusta, alimentando argumentos que foram tentando justificar essa alegada inexistência de autores dramáticos em Portugal: que a "verve dramática" terá sido absorvida pela pulsão lírica; que os dramaturgos não terão condições para poder desenvolver o seu trabalho; que as estruturas de produção teatral padecerão de uma endémica desatenção pela dramaturgia portuguesa...; ou que esta ausência seria até uma forma de atestar o nosso singular modo de ser. Eduardo Lourenço, no seu Labirinto da saudade escreve que em Portugal "tudo se passa como se não tivéssemos interlocutor. (E esta famosa 'forma mentis' reflecte-se na nossa criação literária, toda encharcada de monólogos, o que explica, ao mesmo tempo, a nossa antiga carência de fundo em matéria teatral e romanesca)" (Lourenço, 2000, p. 24). E, assim, a literatura dramática portuguesa ia sendo ciclicamente declarada ausente.

\section{2.}

A partir de meados dos anos 90 do século XX, muitas iniciativas foram provando a vitalidade da criação dramática em Portugal - ou pugnando por ela. O DRAMAT - Centro de Novas Dramaturgias, um 
projecto do TNSJ - Teatro Nacional São João, criado em 1999, coordenado, primeiro, por Fernando Mora Ramos e, depois, por Maria João Vicente, é ainda das mais expressivas. Dos trabalhos do Centro (workshops, oficinas, leituras encenadas, seminários, edição de livros...) resultaram as "dramaturgias emergentes" de autores como Joaquim Paulo Nogueira, Carlos Alberto Machado, José Mora Ramos, Marcela Costa, Helena Miranda, Pedro Eiras, Fernando Moreira, Ângela Marks, João Tuna, António Ferreira e Jorge Louraço Figueira; e um dos mais ricos patrimónios de discussão e saber sobre escrita para teatro em Portugal.

O Projecto Urgências (2004-2007) é outro dos momentos de revitalização de particular relevância. Dirigido por Tiago Rodrigues, numa co-produção Mundo Perfeito, Produções Fictícias e Teatro Maria Matos, nas suas três edições foram levadas à cena mais de duas dezenas de peças curtas inéditas de autores portugueses contemporâneos, tais como Luís Filipe Borges, Susana Romana, Nuno Artur Silva, Filipe Homem Fonseca, Nuno Costa Santos, Pedro Mexia, Tiago Rodrigues, João Quadros, Nelson Guerreiro, Patrícia Portela, Pedro Rosa Mendes, José Luís Peixoto, José Maria Vieira Mendes, Inês Menezes, Joaquim Horta, Maria João Cruz, Mickaël de Oliveira e Rui Cardoso Martins.

Em Novembro de 2010, o Colectivo 84, com direcção de Mickael de Oliveira, organiza o Encontro de Novas Dramaturgias Contemporâneas, oferecendo no SLTM - São Luiz Teatro Municipal a leitura encenada de várias peças, bem como um conjunto de oficinas de tradução, debates, conversas e seminários, numa programação orientada para as "escritas de palco", tendo como âncora uma palestra de Bruno Tackels e sessões de trabalho com os dramaturgos Carlos J. Pessoa, Carlos Costa e José Maria Vieira Mendes. Já com a designação de Festival END, estes Encontros de Novas Dramaturgias farão uma 2a Edição, no TAGV - Teatro Académico de Gil Vicente, em Março de 2015, incluídos no trabalho continuado do Centro de Dramaturgia Contemporânea, dirigido por Fernando Matos Oliveira e criado no âmbito de uma parceria entre o TAGV, o Curso de Estudos Artísticos da Faculdade de Letras da Universidade de Coimbra e o Centro de Estudos Interdisciplinares do Séc. XX (CEIS20). Em 2020, celebrando dez anos sobre o seminal encontro no SLTM, terá lugar o Laboratório END: Investigação, Formação e Criação Artísticas, onde três autores (Lígia Soares, Patrícia Portela e Rui Pina Coelho) acompanharão a 
criação de um projecto para teatro de três jovens autores, num processo de tutoria e escrita acompanhada.

A atribuição de Prémios é, por tradição, uma forma de incentivar de maneira continuada a escrita dramática. Entre outros, o Inatel atribui desde 1992 o Prémio Teatro Novos Textos (nas modalidades Grande Prémio Fundação INATEL e Prémio Miguel Rovisco). Em 1997, o Teatro Aberto associa-se à SPA - Sociedade Portuguesa de Autores para a criação do Grande Prémio de Teatro Português que, para além de um valor pecuniário e da publicação em livro, prevê a encenação da peça vencedora no Teatro Aberto. De 2007 a 2013, o Camões, Instituto da Cooperação e da Língua, em parceria com a Fundação Nacional de Artes - Funarte (Brasil), manteve a atribuição do Prémio de Dramaturgia António José da Silva, visando autores portugueses e brasileiros. Também a partir de 2007 (e até 2011) o Instituto Bernardo Santareno (IBS) da Câmara Municipal de Santarém manteve o Prémio Nacional de Teatro Bernardo Santareno. Também em 2007 e 2008 o Teatro Maria Matos atribuiu o Prémio Maria Matos - Nova Dramaturgia Portuguesa, destinado a incentivar novos autores.

Mas também outros prémios de existência mais esporádica têm ajudado a cumprir o desígnio de apoiar a dramaturgia portuguesa. Entre outros, de dimensão mais local ou efémera, poderíamos destacar o Concurso de Textos Teatrais, promovido pelo TUT - Teatro Universitário do Porto, desde 2012; ou o "Isto não é um concurso", uma iniciativa de 2008, promovida pelos Artistas Unidos - uma companhia de teatro com particulares responsabilidades na renovação da dramaturgia portuguesa, nomeadamente pela publicação de vários textos de autores na sua Revista Artistas Unidos ou na extraordinária colecção "Livrinhos de Teatro" e, muito particularmente, pelo exemplo tutelar que um texto António, um rapaz de Lisboa, de Jorge Silva Melo, veio trazer ao teatro português.

Também o projecto Panos - palcos novos palavras novas, da Culturgest, aliando o teatro escolar/juvenil às novas dramaturgias, tem vindo a instigar a escrita de vários textos, através de uma encomenda anual de peças originais a escritores com obra reconhecida. Desenvolvido, de 2006 a 2017, na Culturgest e dirigido por Francisco Frazão, é desde essa data um projecto coordenado por Sandro William Junqueira para o TNDMII. 
No âmbito da formação, para além das várias oficinas de escrita para teatro que diversas instituições ou autores vão oferecendo, poderíamos destacar a opção em Escritas de Cena que o Mestrado em Teatro da Escola Superior de Teatro e Cinema, dirigida por Armando Nascimento Rosa, de onde resultou a organização do Encontro de Escritas de Cena, em 2011, visando estimular o debate crítico em torno da criação dramatúrgica contemporânea, reunido cerca de trinta dramaturgos portugueses de diferentes gerações.

Mais recentemente, desde 2013, o Teatro Meridional, em colaboração com o Centro de Estudos de Teatro da Faculdade de Letras da Universidade de Lisboa, tem vindo a assegurar o Laboratório de Dramaturgia, dirigido por Natália Luiza, visando a criação de textos inéditos em língua portuguesa.

3.

Este mapa de iniciativas que foram, de alguma forma, ou contrariando a falta de dramaturgia portuguesa ou provando a sua vitalidade está, forçosamente, incompleto. Muitos outros nomes e outras iniciativas poderíamos acrescentar aqui. Ainda assim, e ainda que de forma inacabada, julgo ficar suficientemente esboçado o contexto de emergência do Laboratório de Escrita para Teatro, que coordenei de Setembro de 2015 a Setembro de 2019. Nesses quatro anos, foram escritos vinte e três textos originais para teatro. Desses vinte e três textos, já cinco mereceram estreia em espectáculo ${ }^{1}$. Dessas cinco estreias, três ocorreram no Teatro Nacional D. Maria II (TNDMII).

Este Laboratório de Escrita para Teatro, promovido pelo Teatro Nacional D. Maria II (Lisboa), sob a direcção artística de Tiago Rodrigues, surge, pois, integrado num programa mais lato de apoio a dramaturgias emergentes e ao incentivo à nova dramaturgia portuguesa, consistindo, neste caso, na aproximação de jovens autores dramáticos a processos de partilha, experimentação e colaboração que possam desafiar, influenciar e estimular a escrita original de um texto para teatro.

${ }_{1}^{1}$ São os casos de Terás a promessa de voltar ao lugar de partida, de Ricardo Vaz Trindade, Espaço Mala Voadora, 2017; Quarto Minguante, de Joana Bértholo, TNDMII, 2018; Civilização, de Lígia Soares, Centro de Artes de Lisboa, 2018; Osmarina Pernanbuco não consegue esquecer, Keli Freitas, TNDMII, 2019; Pin My Places, de Mariana Ferreira, TNDMII, 2020. 
Na primeira edição (2015/16), andámos em torno de “Um estado de excepção permanente", sob a égide de Terry Eagleton (2003) e da ideia de que a dramaturgia contemporânea não tem outra hipótese senão dar conta do estado de guerra - um estado de excepção permanente - entre os indivíduos e as instituições de poder. Na segunda edição (2016/17), fomos questionando "A política de tudo", num gesto de homenagem aos cem anos da Revolução de Outubro e de uma inquirição das contradições do século XX, inspirados pela lição de Alain Badiou (2005). Na terceira edição (2017/18), demorámo-nos n' “O quotidiano do homem comum e outras coisas sem importância", conduzidos pela reflexão de Jean-Pierre Sarrazac em torno da poética da dramaturgia contemporânea e das suas "microepopeias dos anónimos". Na quarta edição (2018/19), quisemos "Interromper o real para a ele regressar", confiando nos possíveis gestos políticos que o teatro pode compreender.

Pessoalmente, o Laboratório foi das coisas mais bonitas a que me vi associado. E nunca poderei agradecer o suficiente por me terem permitido assistir ao nascimento destas vinte e três peças de teatro.

\section{ANO 1.}

Tendo o Teatro Nacional D. Maria II recebido cinquenta e cinco candidaturas, cada uma incluindo curriculum vitae, carta de motivação, sinopse para uma peça longa e uma cena de uma peça destinada a ser escrita durante os oito meses de trabalho do laboratório (de Outubro de 2015 a Junho de 2016), foram seleccionados - pela comissão responsável por esse processo (Tiago Rodrigues, Madga Bizarro e Rui Pina Coelho) oito autores: Joana Bértholo, Daniel Gamito Marques, Eduardo Molina, Marta Rema, Sofia Santos Silva, Lígia Soares, Mia Tomé e Ricardo Vaz Trindade.

Para a edição de 2015/2016 - a primeira - titulada “Um estado de excepção permanente", a moldura temática escolhida foi inspirada na obra crítica de Terry Eagleton. "O preço da liberdade é a eterna vagabundagem", afirma este autor em Sweet Violence: The Idea of the Tragic (2003, p. 17). Assim, nessa obra, Eagleton argumenta que na tragédia moderna o protagonista ambiciona a liberdade individual em detrimento de todo o resto, movido por um insaciável Eros. Contudo, para garantir esta liberdade, o homem entregou as rédeas da sua segurança e conforto às instituições que regem a sociedade - e estas, perversamente, fazem 
associar a liberdade individual ao caos e à desordem. Assim, o herói da tragédia moderna, esmagado entre o seu desejo de liberdade e a necessidade de refúgio perante um mundo ameaçador, luta e sofre sozinho expiando os males do mundo capitalista. A dramaturgia contemporânea não tem outra alternativa a não ser dar conta do estado de guerra - um estado de excepção permanente - entre os indivíduos e as Instituições de Poder.

As primeiras conversas - enquadradas numa espécie de ciclo de conferências - versaram sobre estes temas: sobre a ideia do trágico e sobre a violência sistémica na dramaturgia contemporânea; mas também sobre questões mais directamente relacionadas com a escrita dramática na contemporaneidade: a epicização, a rapsodização, a performatividade do texto, a morte do belo animal, a crise do diálogo e do drama... Tudo tópicos que haveriam de invadir uma e outra vez os nossos encontros.

Estas discussões ancoradas numa abordagem mais teórica serviram para lançar a escrita. Assim, procurou-se trabalhar quer avançando para a experimentação, quer recuando para um diálogo com as poéticas e com a tradição teatral, visando encontrar uma metodologia que pudesse responder às diferentes necessidades e características dos diferentes textos.

Os trabalhos incluíram ainda duas sessões com os dramaturgos Jorge Palinhos e Marta Freitas, ambos membros do NuDA - Núcleo de Dramaturgia em Acção, que nos aportaram um primeiro embate crítico com leitores exteriores ao processo. Um outro momento determinante foi o dia que passámos na Livraria 111, no Campo Grande, numa maratona de leituras, lendo todas as peças, das dez da manhã à meia-noite e meia, parando só para comentar os textos com os muitos amigos que ali foram ler, ouvir ou discutir; ou para comer umas fatias de pizza... Em Abril, já perto do momento de conclusão de cada um dos textos, fizemos uma residência de escrita de três dias no Espaço do Tempo, em Montemor-oNovo, um momento absolutamente determinante para o bom sucesso do projecto.

Os textos escritos durante o Laboratório são de uma variedade formal e temática extraordinária. Daniel Gamito Marques, em Europa, atravessa a história da Europa com a história da filosofia europeia, desfiando, com erudição e sensibilidade, pelo meio, a precariedade da investigação e da criação artística. Eduardo Molina, em Portugal: Manifestação em um ato, coloca um coro de cinquenta vozes a vomitar um 
país em plena crise económica e atacado por políticas de austeridade. Marta Rema, em Como um quarto sem telhado ou A alegria, inventa um mundo fantástico sobre a palavra e a linguagem, uma fantasia maravilhosa sobre a infância, de pulsão bruta e original. Sofia Santos Silva, em Privado, um texto de pendor auto-reflexivo, questiona através de elaboradas metáforas o papel da verdade no teatro. Lígia Soares, em Civilização, questiona o papel do artista e do espectador na relação que decidem estabelecer durante o espectáculo, num extraordinário gesto de uso performativo da linguagem. Mia Tomé, em Pensão Glória, num quadro narrativo de inspiração cinéfila, dialoga com os limites do género dramático, compondo personagens que oscilam entre o sonho e o real. Ricardo Vaz Trindade, em Terás a promessa de voltar ao lugar de partida, num formato de alguma extravagância formal, coloca a história de uma mulher em conflito com o seu próprio crescimento para fazer uma crítica ao modelo capitalista e da futilidade da vida contemporânea. Joana Bértholo, em Quarto Minguante, uma obra de longo fôlego, numa escrita inventiva e desafiadora, apresenta um retrato angustiante e claustrofóbico da vida na contemporaneidade, olhando para o modo como vamos tratando a saúde, a morte, a habitação, o trabalho, a família, a felicidade...

Textos que merecem ser descobertos e lidos.

\section{ANO 2.}

No ano da comemoração dos cem anos da Revolução de Outubro, a moldura temática sugerida aos autores tinha por mote o título "A política das coisas". A sugestão que o título mobilizava era suficientemente lata para que a navegação pelo rio das discussões e dos textos tivesse as margens suficientemente perto e, ao mesmo tempo, pudesse ser fluida, livre e rápida. Mas "a política das coisas" revelava também uma certa obsessão com o século XX e com todas as suas extraordinárias contradições. A inspiração colhíamo-la, claro, de Alain Badiou que no capítulo introdutório de O Século (2005), declara: “Por exemplo, eu poderia perfeitamente fazer a seguinte afirmação: o século começa com a guerra de 1914-18 (uma guerra que inclui a Revolução de Outubro de 1917) e termina com o colapso da URSS e o fim da guerra fria. O século curto (setenta e cinco anos), um século fortemente unido. Numa palavra: o século soviético" (BADIOU, 2014, p. 1, t.m.). Em seguida, oferece outras formas de considerar o prolixo século $X X$, encontrando outras narrativas: tendo 
em conta os acontecimentos apocalípticos associados a crimes de Estado: o século dos totalitarismos; ou atendendo ao triunfo do capital e do mercado global: o século liberal. Badiou propõe um "diagnóstico filosófico" do século passado (tal como é caracterizado por Slavoj Žižek), encontrando uma narrativa redentora que se opõe àquela que vê no século $X X$ o fim de tudo: das utopias, das ideologias, da política, tudo sacrificado em prol do proveito económico.

$\mathrm{Na}$ experimentação proposta neste Laboratório de Escrita para Teatro procurava-se prolongar esta ideia aplicando-a ao teatro e à dramaturgia contemporânea. Visava-se, assim, perscrutar as formas de renovação ou reinvenção das utopias (teatrais) do século $X X$, descobrindo as pronunciações mais consentâneas com cada autor para o exercício de um teatro político e para uma efectiva interpelação do real.

Para tal, o Laboratório foi visitado por várias vozes, todas contribuindo para o robustecimento das discussões e para a riqueza discursiva dos textos. Para além de uma sessão exploratória orientada por Ana Coimbra Oliveira (que trabalha com psicologia do movimento), José Neves e Luís Trindade, investigadores no Instituto de História Contemporânea da Faculdade de Ciências Sociais e Humanas da Universidade Nova de Lisboa, orientaram duas sessões dedicadas a "Histórias do Século Vinte: Totalitarismo" e "Histórias do Século Vinte: Narrativas do Socialismo, Narrativas do Capitalismo", respectivamente.

Os dramaturgos Jorge Palinhos e Miguel Castro Caldas, depois de uma análise de cada um dos textos em escrita, vieram oferecer as suas leituras, alimentando, dessa forma, as múltiplas formas de perceber uma mesma coisa. No mesmo sentido, o dramaturgo, actor e encenador Mohamed El Khatib, a dramaturga e formadora brasileira Paula Autran e Tiago Rodrigues orientaram sessões dedicadas à escrita para teatro na contemporaneidade expondo criticamente os seus modos de trabalho.

Em muitas destas sessões participaram também alguns elementos da primeira edição do Laboratório que assim nos trouxeram novidades das suas escritas e muitos contributos para as discussões. Mas estas presenças ajudam também a consolidar a ideia de que neste Laboratório se visa contribuir para a criação de uma comunidade de autores que possam ir discutindo, partilhando e espreitando o trabalho uns dos outros.

À semelhança do que aconteceu na primeira edição deste Laboratório de Escrita para Teatro, um dos momentos mais significativos 
e determinantes terá sido a pequena residência de escrita no Espaço do Tempo, em Montemor-o-Novo.

Os quatro textos que resultaram deste Laboratório são prova da vitalidade e diversidade da dramaturgia portuguesa contemporânea. Comprovam e revelam quatro universos dramáticos de impressiva singularidade e quatro autores plenos de convicções e animados pelas suas certezas - mas também vivamente curiosos, desejosos de desafios e abertos à experimentação. Todos eles se permitiram enovelar nas peças uns dos outros, criando um ambiente de fraterno convívio, debate e provocação.

Cecília Ferreira, actriz e dramaturga no Teatro a Quatro, colectivo que fundou, no Porto, foi merecedora do Grande Prémio de Teatro Português SPA - Novo Grupo 2013 pela peça A Acompanhante. Em Mãos ao Alto: Ensaios Para Entrar no Paraíso coloca um Homem e uma Mulher a prepararem uma exposição de fotografias na sala de sua casa. Por entre a montagem do evento vão desfiando as suas obsessões privadas, as mínimas e as públicas, e, mais substantivamente, vão criando uma narrativa para as suas vidas, fazendo colapsar ficção e realidade, dissimulando, neste gesto, a idade, a solidão e a (possível) morte de uma filha. Um luto distópico que levanta um sórdido enigma por entre todo o texto.

Fernando Giestas, director (com Rafaela Santos) da Amarelo Silvestre - Associação Cultural, sedeada em Canas de Senhorim, continua uma exploração de uma linguagem cénica alicerçada num entendimento lúdico da palavra e das suas propriedades fonéticas e musicais, emoldurada num universo de uma estranheza devedora tanto da herança do non-sense ou do absurdo como da tragédia. Assim, Os Lugares de Onde Vemos Sentados é um exercício de reflexão sobre o próprio acto de assistir a um espectáculo de teatro, atravessado com um pensamento sobre o próprio acto de escrever para teatro.

Isabel Milhanas Machado, actriz e dramaturga, com alguns trabalhos já apresentados em Lisboa, tais como o monólogo Mariana (2014) ou Robes (2016), apresenta em Os Ratos uma espécie de tragédia do quotidiano. Assistimos, assim, a um dia na vida de cinco jovens amigos. Recuperam-se algumas marcas clássicas da tragédia para as subverter e reconfigurar: a jornada fatal, a iminência da catástrofe ou a chegada do misterioso desconhecido. Tudo isto serve para fazer um retrato heteróclito de uma geração enleada com rendas em atraso, precariedade laboral e 
indefinição quanto ao futuro - mas também uma geração que tenta, a todo o custo, não perder a sua identidade.

Em Treva ou Os Princípios da Higiene Funcional, Sabrina D. Marques, dramaturga, crítica e investigadora com interesse particular em cinema, convida ao convívio com uma voz encarcerada num hospital e a um mergulho nas profundezas de uma mente que luta com a memória e com o passado. Num vórtice derivativo de impressivo lirismo e força, alinhamse, como se de um diário se tratasse, internamentos e altas, memórias, medos e vontades. Uma viagem de bruta poesia e realidade.

Quatro peças extraordinariamente diferentes. Minuciosamente buriladas, discutidas, ensaiadas, experimentadas, revistas, pensadas...

\section{ANO 3.}

Jean Pierre Sarrazac (2011, p. 65) nomeia a dramaturgia do fait divers como aquela que tem "o mérito de estabelecer dia a dia um catálogo daquilo que Barthes chama 'o inexplicável contemporâneo'". No mesmo sentido, para este crítico, os pequenos acontecimentos, os eventos banais protagonizados pelos homens e mulheres comuns, a "microepopeia dos anónimos, tem no teatro contemporâneo o lugar que o mito tinha na tragédia antiga" (SARRAZAC, 2011, p. 67). Esta reflexão parte, claro, da crise szondiana e da alegada falência do modelo do drama absoluto e primário que terá reinado - na argumentária szondiana - do século XVI ao final do século XIX. A esse drama absoluto e primário chama-lhe Sarrazac "drama-na-vida". Ao novo paradigma dramático, um drama em crise permanente, um drama que se oporá ao "critério aristotélico-hegeliano do 'belo animal' que supõe ordem, duração, completude" (SARRAZAC, 2011, p. 40), corresponderá a designação de "drama-da-vida".

O drama da vida não se limita àquilo que Sófocles chama uma "jornada fatal": ele contraria as unidades de tempo, de lugar e até de acção e a sua duração cobre toda uma vida. Para abarcar a totalidade duma existência, o drama-da-vida recorre à retrospecção - até ao privilégio do teatro épico - e a procedimentos de montagem. De facto, o drama-da-vida marca uma mudança decisiva na medida do drama, quer dizer, na sua duração, mas também no seu ritmo interno. $O$ drama-na-vida correspondia intimamente a um momento da existência dos heróis; a duração do drama-da-vida é inversamente 
proporcional à intensidade da existência do homem comum. (SARRAZAC, 2011, p. 40)

Foi com esta moldura que iniciámos a terceira edição deste Laboratório de Escrita. Na chamada a participantes, apresentámos o tema da seguinte forma, lembrando um dos mais notáveis "homens comuns" da história da literatura dramática: o malogrado Willy Loman.

\begin{abstract}
A 27 de Fevereiro de 1949, na sequência da estreia de Morte de um caixeiro-viajante, Arthur Miller publica, no jornal New York Times, o ensaio "A tragédia e o homem comum". Nesse texto, Miller reclamava a dignidade do homem comum e da sua vida anónima e banal, colocando-o no centro da vertigem trágica. Com efeito, e nesse sentido, a segunda metade do século XX trará para um lugar central da dramaturgia uma nova tipologia de herói: o desalinhado, o marginal, o rebelde sem causa, o zé-ninguém, pulverizando definitivamente a noção de herói trágico. Este ímpeto trará o quotidiano, o insignificante e o ordinário para o palco, afastando-nos dos dias fatais das histórias trágicas, e depositando-nos definitivamente nos dias fractais de um infra-dramático que testemunha e narra a epopeia da vida humana.
\end{abstract}

Estas foram as questões que andaram na teia das conversas durante estes nove meses - o tempo de gestação e maturação das peças aqui publicadas. Ainda que o refrão tenha sido em torno destas questões, a verdade é que a especificidade de cada um dos textos foi assumindo, à medida que o tempo passava, um protagonismo cada vez maior.

Durante todo este tempo, entre discussões, debates, refeições, leituras, escrita e reescrita, os seis dramaturgos tiveram a oportunidade de discutir metodologias de trabalho e outras formas de entender o lugar da escrita para teatro com vários autores. Assim, tiveram lugar sessões de trabalho com Amir Reza Koohestani, Jorge Palinhos, Joana Craveiro, José Maria Vieira Mendes e David Carnevalli. Todos eles aportaram para o grupo de trabalho formas muito díspares de entender a relação da escrita com o teatro e noções muito singulares de dramaturgia. Todas elas provocadoras e desafiantes - e que deixaram impressivas marcas na escrita dos textos.

À semelhança do que aconteceu também na segunda edição do Laboratório, estas sessões foram abertas aos participantes das edições anteriores, robustecendo e espevitando a teia de cumplicidades que, entretanto, se foram criando entre os autores participantes - e 
consolidando a ideia da criação de uma comunidade de autores que possa ir crescendo na companhia fraterna e crítica um dos outros.

Para além de uma sessão de leitura de todos os textos, aberta a convidados, no Salão Nobre do Teatro Nacional D. Maria II - um momento de pertinente abertura dos textos a um diálogo com um grupo de interlocutores mais lato que serviu para confirmar certezas ou para ajudar à reformulação de hesitações -, um dos momentos mais determinantes desta edição foi - mais uma vez - a pequena residência de escrita no Espaço do Tempo, em Montemor-o-Novo. Aí, mais uma vez, a recolha que este maravilhoso espaço de trabalho propicia ajudou a que os textos encontrassem uma versão próxima da que veio a ser a final.

Um dos aspectos mais notórios dos textos aqui reunidos é a forma como a memória se tornou um tema central a grande parte dos textos. De diferentes maneiras, é certo, mas, ainda assim, de uma recorrência assinalável. É certo que nove meses de encontros e conversas regulares acabam sempre por promover algumas contaminações. Mas a verdade é que a "memória" ou a "pós-memória" (para usar o termo de Marianne Hirsch que tão operativo tem sido para o trabalho artístico de Joana Craveiro, entre outros), tem surgido nas artes performativas portuguesas de forma muito visível. Desde By Heart, de Tiago Rodrigues ao Museu Vivo de Memórias Pequenas e Esquecidas, de Joana Craveiro/Teatro do Vestido, o trabalho em torno da memória tem sido um dos traços mais impressivos da cena nacional. Bastava lembrar também a trilogia de André Amálio (Portugal não é um país pequeno, Passa-porte e Libertação) sobre o passado colonial português; ou Eu uso termotebe e o meu pai também, de Ricardo Correia, sobre comunidades de operários fabris e os processos de transmissão do trabalho em Portugal.

Ora de forma mais documental, ora de forma mais íntima e introspectiva, a memória surge como matéria dramatúrgica.

Os textos escritos durante esta edição do Laboratório davam conta, creio, disso mesmo. Assim, de Keli Freitas temos Osmarina Pernambuco Não Consegue Esquecer, uma inventiva composição sobre processos de apropriação da memória, num habilidoso e generoso jogo entre a ficção e a realidade, em torno de uma personagem que se recusa a esquecer Osmarina Pernambuco, uma mulher brasileira nascida em 1919 e que escreveu diários toda a sua vida. 
Pode ser que um dia, da jovem estreante Maria da Paz Carvalho, é um texto de uma liberdade formal excepcional, convidando o leitor/espectador a um passeio por uma cidade edificada com fragmentos e relampejos de memória. Uma peça para caminhantes que não sabem onde vão e que, assim, se permitem à visitação das cidades que trazem na lembrança.

Em Antes Que Ela Se Apague, de Mirró Pereira, a memória assume, também, lugar central. De pulsão pirandeliana, uma Autora convoca um homem e uma mulher para a ajudarem a recordar/inventar a história de um casal e da casa em que viveram, rodeados dos seus muitos objectos. Entre o abismo do futuro e o manto do passado, o casal vai tentando encontrar o seu amor e a sua própria razão de viver.

A Noite Mais Longa Do Ano, de Rafaela Lacerda, acompanha a relação de dois homens durante três anos, sempre na noite da véspera de Natal. Não sendo exactamente sobre a memória, trata-se de um texto que explora as dificuldades em definir o amor e em saber amar. E em como as coisas realmente importantes se escondem muitas vezes debaixo da superficialidade dos dias...

Em Call Center, uma peça coral para sete atores, Ricardo Correia completa o díptico sobre o Trabalho, iniciado com o espetáculo Eu uso termotebe e o meu pai também, reflectindo sobre "a condição de operário e a sua emancipação bem como as mutações da sua identidade ao longo de várias gerações, desde os remotos operários fabris até aos novos operários do século XXI", tal como afirma o autor. Aqui, mergulhamos no universo dos callcentristas, misturando depoimentos reais com invenção teatral, num ardiloso jogo de denúncia da precariedade laboral.

Por fim, em O Reino do Fundo, Tatiana Salem Levy perscruta as raízes identitárias de um Brasil urbano e que se alicerça num outro país, um país de outras tradições e imaginários. É um texto sobre a culpa burguesa e sobre os complexos de classe, em torno da visita de uma jovem carioca, Camila, ao Maranhão para se reencontrar com a sua antiga ama, Dalva. Um texto de enorme potência que deve tanto à fantasmagoria como à inscrição política.

Seis peças de teatro com muitos refrãos comuns, é certo - mas todas com vigorosa identidade e que atestam, creio, o momento de particular interesse que vai vivendo a dramaturgia portuguesa contemporânea. 


\title{
ANO 4.
}

\begin{abstract}
Num mundo em que a arte tem cada vez menos relevância e em que vai perdendo a sua capacidade de inscrição na esfera pública, que teatro precisamos? Que teatro precisamos para resgatar o mundo de uma escatologia anunciada? Que estratégias de resistência podemos nós ainda descobrir? Que acções nos restam ainda para que consigamos escapar à doce violência da voragem dos dias? Andar de mãos dadas com amor, passear pela cidade sem rumo, conversar noite dentro?... Que estratégias de interrupção do real nos restam? Como podemos nós interromper o real para a ele voltarmos mais fortes e mais limpos?
\end{abstract}

Foi com este enquadramento que nos abeirámos da quarta edição deste Laboratório: "Interromper o real para a ele regressar". Para esta edição quisemos explorar a função da arte, e do teatro em particular, como um instrumento de reescrita do mundo, como uma forma de interromper as rotinas do pensamento comum e de abrir brechas na vida. "Nada é da forma que fica": a inspiradora epígrafe de Heiner Müller incita a que possamos imaginar sempre mundos outros e atrevermo-nos a pensar novas realidades. Não para que fujamos ou para que nos escapemos da nossa própria realidade, mas para que possamos exercitar o músculo da imaginação, da resistência e da inteligência de modo a podermos transformar o mundo. Pensar a utopia como o combustível do hoje.

Os gestos não têm de ser grandes, desde que sejam verdadeiros. Dançar agarrado ao amor verdadeiro, bruxulear na noite de mão dada com amigos, sentar numa esplanada a ouvir o sangue andar de um lado para o outro - são estratégias de interrupção do mundo que nos permitem voltar a ele de forma mais justa e mais vertical. Com efeito, "nada é da forma que fica" - estamos sempre a um passo da mudança. E isso, tanto pode ser paralisador como extremamente libertador.

Os cinco textos aqui publicados resultaram todos de maturadas viagens por uma estrada cheia de nevoeiro. Bruno Fraga Braz, em Oito ou Caos, oferece-nos uma inquietante reflexão sobre um tema que, por vezes, preferiríamos ignorar e que nos obriga a questionar o nosso habitual papel de espectadores e juízes do mundo. Uma criança é esquecida num carro, num dia de calor. A criança morre. Como se julga um caso destes? Como se vive para além disto? Como se apazigua a tempestade interior? 
Henrique Bispo, em $O$ Elefante ou o inevitável caminho do esquecimento, enceta uma alegoria sobre a necessidade de esquecer para se poder andar em frente com a vida, cruzando um imaginário de grande fertilidade cénica com a escavação de memórias mais substratas. Uma viagem pessoal que encontrará eco, estou seguro, em muitos dos processos de luto que todos vamos tendo de fazer ao longo da vida.

Que le spectacle commence (Detalhes de uma ilusão), de Lara Pires, simulando um drama familiar onde convivem três irmãs, trata-se, em rigor, de uma dança espectral sobre a memória e o trauma, numa teia de intrincadas relações de afecto. Um mergulho no passado pautado por uma urgente necessidade de libertação.

Em A Mancha, Lúcia Pires ensaia, numa linguagem devedora de um insólito teatro do absurdo e de uma extraordinária jovialidade linguística, uma distopia sobre a desumanização e a necessidade de nos deixarmos afectar pelo humano que ainda vamos conseguindo preservar. Um texto intrigante que vai fazendo aparecer, lentamente, a gravidade dos temas que convoca.

Finalmente, Pin my Places é uma espécie de mapa afectivo de Mariana Ferreira. Nele, a autora vai buscando traços de si na pegada digital que vai deixando online, cruzando essa sua existência com as suas próprias passadas e com os seus desejos de futuro. Um texto que disfarça com humor e invenção uma enorme urgência de discutir processos identitários e a memória.

À semelhança do que foi acontecendo nas outras edições deste Laboratório, para além dos muitos momentos de leitura e discussão dos textos, muitas das sessões foram asseguradas por artistas e académicos que vieram ajudar ao processo de escrita. Assim, nesta edição os autores puderam escutar e trabalhar com o autor e encenador francês Pascal Rambert, com a psicóloga de movimento Ana Coimbra Oliveira, com a artista multidisciplinar Marta Bernardes, com a romancista e dramaturga Joana Bértholo (que participou como autora na primeira edição do Laboratório) e também com os dramaturgos Tiago Rodrigues, José Maria Vieira Mendes e David Geselson. Muitas destas sessões foram também participadas por vários elementos de outras edições do Laboratório, ajudando assim a consolidar a ideia de que neste Laboratório se visa contribuir para a criação de uma espécie de comunidade de autores que possam ir, de forma cúmplice, partilhando as suas viagens. 
Para além das sessões "regulares", os textos foram também lidos numa longa maratona na Livraria Ferrin, em Abril, onde os autores os puderam ouvir e discutir, perante amigos e convidados. De enorme contributo, em Maio, foi também a residência de escrita levada a cabo no Espaço do Tempo, em Montemor-o-Novo - parceiros dilectos desde a primeira edição deste Laboratório - , onde os textos se aproximaram da sua forma final.

\section{POST SCRIPTUM}

Um Laboratório como este move-se entre dois polos de um mesmo eixo: o da Garimpagem e o da Carpintaria. Há, em todo o processo, uma necessidade de selecção e de prospecção que se traduz na busca de uma voz singular, de uma escrita original, na escrita para teatro. Mas, por outro lado, também é necessário um moroso trabalho de Carpintaria, que se traduz na necessidade de auxiliar cada autor a encontrar a sua própria voz e de descobrir os instrumentos necessários para que cada um escreva o texto que quer escrever. Entre os dois, balança-se.

Há outros dois polos que podem ajudar a organizar o trabalho de um laboratório como este: o da escala íntima e o da potência pública. Quer isto dizer que os textos devem ter uma gravidade na escala íntima dos seus autores. Mas, ao mesmo tempo, devem também apontar para uma inscrição na coisa pública, para uma potência no seu papel de agentes de transformação do mundo. Como é que isso se faz? Boa pergunta.

E depois, a coisa mais importante que percebi ao longo destes quatro anos: dizer só a verdade, sem versos nem rodeios. Dizer só a verdade. Faz-se assim: desenha-se a verdade com um giz no chão, um círculo, nem muito grande nem muito pequeno. Desenha-se esse círculo de giz, dá-se um passo, entra-se dentro dele e não se sai de lá. Por nada. Deixamo-nos estar dentro da verdade. Deixamo-nos estar. Não fazemos nada. Só temos de ter muito cuidado com a ponta dos pés para não esborratarmos o giz.

Se usei, algumas vezes, nestas linhas, um plural majestático e frases de verdades supostamente redondas, espero que o leitor não me leve demasiado a sério: são tiques de linguagem que servem só para dar um ar mais perene a algo que não passa de uma impressão íntima. E, em rigor, não tenho desejo algum de que se tornem perenes. Não tenho grandes certezas. Estas afirmações aparecem aqui como confissões públicas de uma 
das grandes aprendizagens que fiz ao longo dos quatro anos de coordenação deste Laboratório (e nesta última edição com o apoio de Keli Freitas): que nada é realmente importante se não for verdadeiro. E nem tenho sequer grandes certezas em relação a isto. No que à escrita para teatro diz respeito, muito menos. Não há hoje poéticas universais. Não há regras nem manuais que nos possam guiar. A "crise permanente" que caracteriza a escrita dramática impele-nos a um processo de contínua reinvenção. E isso, tanto pode ser paralisador como extremamente libertador. Não há regras. Escrever para teatro, hoje, é ir desbravando caminho por meio de uma floresta que anda. Lembro-me de, há tempos, ouvir na rádio um escritor - não me lembro qual - a citar um outro escritor - não me lembro qual - a dizer qualquer coisa como: escrever é como conduzir numa estrada cheia de nevoeiro. Vamos avançando sempre em frente vendo só o pouco que a luz dos faróis consegue iluminar. Suspeitamos que há mais estrada, mas, em rigor, não a vemos. Esta imagem, parece-me, aplica-se perfeitamente à escrita para teatro hoje. Vamos abrindo caminho.

Claro que a ausência de regras também pode paralisar. Se não há regras, o que é que faz de um texto qualquer um texto para teatro? Qual é, afinal, a especificidade do texto dramático (para recordar Osório Mateus)?

Pensar o texto para teatro, hoje, assemelha-se muito, creio, àquele momento em que conduzimos numa qualquer estrada e passamos por um carro abandonado que terá tido um qualquer acidente: a carroceria ardeu, já foi vandalizado, levaram-lhe o motor, roubaram-lhe os pneus, já não tem volante - mas, contudo, quando passamos por ele, na estrada, alguém exclama: "Ena, viste aquele carro?". Aquele "carro"! Para todos os efeitos, ainda é um carro, mesmo que não tenha volante, rodas, motor, assentos... mesmo que não ande e, em suma, não tenha nenhuma das tradicionais características que habitualmente definem um "carro". Assim está, creio, a escrita para teatro: está na berma da estrada, a carroceria ardeu, já foi vandalizada, levaram-lhe o motor, roubaram-lhe os pneus, já não tem volante - mas, contudo, ainda é "para teatro". Mesmo sem nenhuma das tradicionais características que habitualmente a foram definindo.

E, por isso mesmo, nada é realmente importante se não for verdadeiro. Ao longo destes quatro anos vi serem criadas vinte e três peças de teatro. Todas diferentes, claro, e todas a responderem às demandas dos seus autores. E, no processo, fomos percebendo que, sem verdade, sem 
urgência íntima, não há malabarismo nem habilidade técnica que nos salve. O mundo está cheio de coisas bem feitas. É preciso que haja mais coisas honestas.

\section{REFERÊNCIAS BIBLIOGRÁFICAS}

BADIOU, Alain. Le Siècle. Paris : Éditions du Seuil, 2005.

EAGLETON, Terry. Sweet Violence: The Idea of the Tragic. Oxford: Blackwell Publishing, 2003.

LOURENÇO, Eduardo. "Psicanálise mítica do destino português" in O Labirinto da saudade. Lisboa: Gradiva, 2000.

MATEUS, Osório. “Especificidade do texto dramático", De Teatro e outras escritas. Lisboa: Quimera, 2002, pp. 105-115.

REBELLO, Luiz Francisco. Breve história do teatro português (5 $5^{\mathrm{a}} \mathrm{ed}$.). MemMartins: Publicações Europa-América, 2000.

SARRAZAC, Jean-Pierre. O Outro diálogo: elementos para uma poética do drama moderno e contemporâneo. Évora: Licorne, 2011.

SARRAZAC, Jean-Pierre. Poétique du Drame Moderne: De Henrik Ibsen à Bernard-Marie Koltès. Paris: Éditions du Seuil, 2012.

Recebido em 1 de novembro de 2020

Aprovado em 29 de novembro de 2020

Licença: (ㄷ) (i) (요

Rui Pina Coelho

Professor e diretor do Centro de Estudos de Teatro da Faculdade de Letras da Universidade de Lisboa. Licenciatura em Línguas e Literaturas Modernas, variante de estudos Portugueses e Ingleses na Faculdade de Ciências Sociais e Humanas da Universidade Nova de Lisboa, Mestre em Estudos de Teatro na Faculdade de Letras da Universidade de Lisboa e Doutoramento em Doutorado em Estudos Artísticos - Especialidade em Estudos de Teatro.

Contato: ruipinacoelho@gmail.com

(D): https://orcid.org/0000-0002-4065-6421 